\title{
Isolation and Partial Characterization of Two Porcine Spleen Ferritin Fractions with Different Electrophoretic Mobility
}

\author{
W. van Gelder, ${ }^{a}$ M. I. E. Huijskes-Heins, ${ }^{a}$ D. Klepper, ${ }^{b}$ W. L. van Noort, ${ }^{a}$ \\ M. I. Cleton-Soeteman and H. G. van Eijk ${ }^{a}$ \\ adepartment of Chemical Pathology, Erasmus University Rotterdam, Rotterdam, \\ The Netherlands. 'Laboratory of Solid State Chemistry and Materials Science, Eindhoven \\ University of Technology, Eindhoven, The Netherlands
}

\begin{abstract}
Ferritin isolated from porcine spleen could routinely be separated in two fractions on nondenaturating gradient gels. Both fractions could be isolated with a purity of $96 \%$ when applied to two serially linked columns, each $200 \mathrm{~cm}$ in length, packed respectively with Sepharose $4 \mathrm{~B}$ and Sepharose $6 \mathrm{~B}$. Both fractions were similar as judged by electron microscopy. Assessed biochemically fractions were equal with respect to subunit composition, iron and phosphorus content, as well as amino acid composition (with the exception of $N$-acetylglucosamine). Carbohydrate analysis showed that the fraction with an apparent mass of $440 \mathrm{kDa}(=\mathrm{FFL})$ contained $1.8 \%(\mathrm{w} / \mathrm{w})$ glycans, whereas the fraction with an apparent mass of $670 \mathrm{kDa}(=\mathrm{FFH})$ contained nearly five times as much (neutral) sugar residues $(8.9 \%, \mathrm{w} / \mathrm{w})$ and 10 times as much sialic acid. This difference in amount of carbohydrate side chains might explain the dissimilarity in electrophoretic mobility of the two fractions. COMP BIOCHEM PHYSIOL 115B;2:191-199, 1996.
\end{abstract}

KEY WORDS. Ferritin glycosylation, amino acid composition, porcine spleen, electron microscopy, electrophoresis, chromatography, amino acid composition, carbohydrate analysis

\section{INTRODUCTION}

Prokaryotic and eukaryotic cells all contain ferritin as their major iron storage protein. According to the "classical" idea, ferritin protein is composed of 24 subunits of two types: the H-type of circa $21 \mathrm{kDa}$ and the L-type of circa $19 \mathrm{kDa}$ amounting to a total mass of circa $450 \mathrm{kDa}$. Inter- and intraspecies heterogeneity was explained by the various proportions in which the subunits assemble. Arranged with $4: 3: 2$ symmetry, the subunits form a hollow shell, in which up to 5000 iron atoms can be stored $(1,13,18,21)$.

Although it was accepted that serum ferritins were glycosylated $(11,12)$ and tissue ferritins were not $(9)$, the existence of a small amount of associated carbohydrates in horse spleen (35), and in human spleen, liver and heart have been reported $(14,24,31)$. The subject however, is still under discussion. Refinement in biochemical research resulted from 1980 onwards in reports on horse heart ferritins of different molecular weights due to either assembly of more than 24 subunits $(26,27)$ or to attachment of a non-ferritin compo-

Correspondence to: M. I. Cleton-Soeteman, Department of Chemical Pathology, Erasmus University Rotterdam, Dr. Molewaterplein 50, 3015 GE Rotterdam, The Netherlands. Fax(31)10-4360615.

Received 4 May 1995; revised 23 February 1996; accepted 12 March 1996. nent in rabbit liver ferritin (32). Passaniti et al. (28) report on chicken liver ferritin intermediates of lower molecular weight next to the common ferritin of around $440 \mathrm{kDa}$. Moreover, other authors describe either a subunit of different amino acid composition in rat liver (4), or different classes of subunits besides the well known $\mathrm{H}$ and $\mathrm{L}$ subunits (10).

Our current research on porcine brain iron metabolism requires ferritin of a high purity. After improvement of a standard method for the isolation and purification of porcine ferritin, we found next to the expected $440 \mathrm{kDa}$ band ( $=$ FFL) a substantial fraction of the ferritin $(30 \%)$ to be located in an iron-containing band around $670 \mathrm{kDa}$ $(=\mathrm{FFH})$. At first, we considered this a phenomenon typical for porcine spleen ferritin. However, testing (commercial) horse spleen ferritin and human placental ferritin (available in our lab) we also found the two fractions in about the same ratio, i.e. 7 to 3 . We were aware of the fact that the band around $670 \mathrm{kDa}$ might be a dimeric form of ferritin as described by Williams et al. (39). Comparing samples (prepared as done by these authors) of the two fractions by electronmicroscopy we did not observe a typical band of molecular dimers. Therefore, we decided upon a further analysis of the two porcine spleen ferritin fractions and to report on the composition of their subunits, amino acids 
and carbohydrates and on their morphology as visualized by electron microscopy.

\section{MATERIALS AND METHODS Materials}

Fresh porcine spleens were obtained from the local slaughterhouse, transported and kept on ice until further processing. Horse spleen ferritin, BSA (bovine serum albumin) and PMSF (Phenylmethylsulfonylfluoride) were obtained from Sigma (U.S.A.). Sepharose 4B, Sepharose 6B and Sephadex G 200 were purchased from Pharmacia/LKB (Pharmacia, Sweden). All other chemicals were of the highest purity commercially available.

\section{Isolation and Subfractionation of Porcine Spleen Ferritin}

Isolation method 1: Porcine spleen ferritin was isolated according to a method adapted from Penders (29). Briefly, after removal of fat and connective tissue, the spleen was rinsed in $0.15 \mathrm{M} \mathrm{NaCl}\left(4^{\circ} \mathrm{C}\right)$ and homogenized (Ultraturrax, Janke \& Kunkel). The homogenate was heated $\left(80^{\circ} \mathrm{C}, 5 \mathrm{~min}\right)$, rapidly cooled and centrifuged in a Beckman $\mathrm{J}-21 \mathrm{C}$ equipped with a JA 14 rotor at $3000 \mathrm{~g}$ for $45 \mathrm{~min}$. The supernatant was centrifuged in a Beckman L-70 equipped with $50.2 \mathrm{Ti}$ rotor at $78,000 \mathrm{~g}$ for $1 \mathrm{~h}$ and the resulting pellet resuspended in $0.15 \mathrm{M} \mathrm{NaCl}$ and centrifuged at $7000 \mathrm{~g}$ for $1 \mathrm{~h}$. The ferritin containing supernatant was then centrifuged at $78,000 \mathrm{~g}$ for 1 hour. The last two centrifugation steps were repeated and finally the pellet was resuspended in $0.15 \mathrm{M} \mathrm{NaCl}$ containing $0.01 \% \mathrm{NaN}_{3}$ and centrifuged again $(78,000 \mathrm{~g}, 1 \mathrm{~h})$. All centrifugation steps were performed at $4^{\circ} \mathrm{C}$.

Isolation method 2: Human placental ferritin and porcine spleen ferritin were isolated according to the procedure described by Konijn et al. (23).

\section{Preparation and Operation of the Combined Sepharose 4B and Sepharose 6B Columns}

To separate the two ferritin fractions, we experimented with a number of gels and column types. The best results were obtained using two columns, packed with Sepharose 4B $(207 \times 2 \mathrm{~cm})$ and Sepharose $6 B(200 \times 1.8 \mathrm{~cm})$ respec. tively. Column dimensions required the level of the column outlet tubing to be adjusted during packing of the gel in order to prevent packing pressure exceeding $80 \mathrm{~cm} \mathrm{H}_{2} \mathrm{O}$. Samples were loaded on the Sepharose $6 \mathrm{~B}$ column, eluted with a $0.05 \mathrm{M}$ Tris-HCL buffer $(\mathrm{pH} 8.0)$ and fed directly into the Sepharose 4B column. Both columns were serially linked with small diameter tubing $(\phi 0.7 \mathrm{~mm})$ to prevent remixing of the already partially separated proteins. Pure ferritin fractions were collected and concentrated by ultracentrifugation in a Beckman L-70 equipped with $50.2 \mathrm{Ti}$ rotor at 78,000 $\mathrm{g}$ for $1 \mathrm{~h}$.

\section{Polyacrylamide Gel Electrophoresis}

Native (non-denaturating) polyacrylamide gel electrophoresis (PAGE) and sodium dodecyl sulfate (SDS)-PAGE were performed on a mini protean system 2 (Bio Rad, the Netherlands) according to manufacturer's instructions. Similar analyses were also performed with $4-15 \%$ and 8$25 \%$ gradient gels (Pharmacia/LKB) on a Phastsystem (Pharmacia/LKB). Gels were stained for protein with Coomassie Blue R 250 according to manufacturer's instructions. Iron staining was performed according to Chung (7) using Ferene S. Gels were analyzed and quantitated using an Ultroscan XL enhanced laser densitometer (LKB, the Netherlands).

\section{Tricine-SDS Polyacrylamide Gel Electrophoresis}

Analyses of $\mathrm{L}$ and $\mathrm{H}$ subunit ratios in the porcine spleen ferritin fractions were performed on Tricine-PAGE $(16.5 \%$ $T$ and $3 \% \mathrm{C}$ ) gels according to Schägger \& Jagow (34). The $16.5 \%$ Tricine SDS-PAGE (as compared to standard SDSPAGE) resulted in a more distinct separation between both the 19 and $21 \mathrm{kDa}$ subunits and allowed a better densitometric analysis of the subunit ratio.

\section{Protein Iron and Phosphorus Determination}

Protein measurements were performed as described by Bradford (6), using different concentrations of BSA as a standard.

Ferritin iron was determined according to a method adapted from Harris (19) using Ferrozine (Sigma, U.S.A.). To a $100-\mu 1$ sample an equal amount of $37 \%(w / v) \mathrm{HCl}$ was added, mixed and left to stand for $15 \mathrm{~min}$. Next, 100 $\mu 1$ L-ascorbic acid $(0.14 \mathrm{M}), 0.5 \mathrm{ml}$ sodium acetate (saturated) and Ferrozine $(10 \mathrm{mM})$ were added to this mixture. After 10 min the absorbance at $562 \mathrm{~nm}$ was measured and compared to a range of standard $\mathrm{Fe}$ (III) solutions.

Biochemical assessment of the amount of phosphorus in ferritin was performed according to Ames $(2,5)$.

\section{Electron Microscopy}

For morphological studies, ferritin solutions were diluted to protein concentrations between 4 and $20 \mu \mathrm{g} / \mathrm{ml}$. Nylon grids (60 mesh) were covered with a pyoloform film with multiple holes and coated with carbon. Samples were brought on the grids by touching them on the surface of a drop of the ferritin solutions. Addition of a spreading agent was omitted as this did not have influence on the results. Excess fluid was drained off with filter paper and the specimens were air-dried. Electron micrographs were taken with a Transmission Electron Microscope (TEM) JEOL 2000 FX at $80 \mathrm{KV}$ with the use of an anticontamination device at plate camera magnification of $20,000 \times$. 


\section{Determination of the Iron to Phosphorus Ratio with Electron Probe Microanalysis (EPMA)}

For analytical purposes, grids were prepared the same way, EPMA was carried out (8) with a Transmission Electron Microscope (TEM) JEOL $2000 \mathrm{FX}$ at $80 \mathrm{kV}$, with the use of an anticontamination device. The TEM was equipped with an X-ray detector with a high purity germanium crystal and ultrathin window. The detector was coupled to a Tracor Northern 5500 System. The specimen (ferritin) was observed in a single tilt holder with a graphite specimen retainer at a take-off angle of $35^{\circ}$. Ferritin suspensions were placed directly on the grids and air-dried. Multiple analyses were performed during $100 \mathrm{sec}$ (irradiated area: $0.75 \mu \mathrm{m}^{2}$ ) on that part of the ferritin suspension that covered the holes in the pyoloform film. Another set of analyses was performed under the same instrumental conditions on that part of the ferritin suspension that was covering the pyloform film. Horse spleen ferritin served as a calibration standard. Electron micrographs were made of each fraction at a magnification of $500,000 \times$.

\section{Analyses of Carbohydrate and Amino Acid Composition}

Purified porcine spleen ferritin fractions were analyzed for the presence of glycans in a technique according to $\mathrm{Van}$ Noort \& Van Eijk (39) on a LKB Alpha Plus 4151 (Cambridge, U.K.) equipped with a $60-\mathrm{cm}$ column $(\phi 2.4 \mathrm{~mm})$ packed with Ultropac 11 resin (Pharmacia Biotech, Sweden).

Analyses of $\mathrm{N}$-acetylglucosamine and amino acids were performed using a method described by Van Eijk \& Van Noort $(36,38)$ on a Pharmacia Biochrom 20 (Pharmacia, Cambridge, UK) equipped with a $20 \mathrm{~cm}$ column $(\phi 4.6 \mathrm{~mm})$ packed with Ultropac 8 resin (Pharmacia Biotech, Sweden). Results of duplicate chromatographic runs varied less than $3 \%$ within one sample (37).

\section{Sialic Acid Quantification}

Following carbohydrate analysis, the amount of sialic acid in "crude" ferritin and both ferritin fractions was assessed according to a technique described by Horgan (22). This analysis is a modification of the method of Aminoff yielding a 20 -fold increase in sensitivity (3). Hydrolysis was performed in $50 \mathrm{mM}$ sulfuric acid at $98^{\circ} \mathrm{C}$ for $105 \mathrm{~min}$. The thiobarbituric acid assay (applying 100-3000 ng sialic acid) was performed in n-butanol at $549 \mathrm{~nm}$. Bi-bi-antennary human transferrin with four sialic acid residues was used as standard.

\section{Alpha-2-Macroglobulin Assay}

Ouchterlony double immunodiffusion was accomplished in sodium barbiturate buffered $1 \%$ Agarose (ICN, The Netherlands) and stained with Amido Black. Rabbit anti- porcine-serum protein antibodies (obtained from Nordic, The Netherlands) were used because neither porcine alpha2-macroglobulin nor its antibody are commercially available. As alpha-2-macroglobulin is a serum protein, one would expect a reaction between alpha-2-macroglobulin and anti-serum protein antibodies.

\section{Preparation of Anti-FFL and -FFH Antibodies}

Anti-FFl and -FFH antibodies were prepared by injecting purified protein in male New Zealand White rabbits using Specol (Central Veterinary Institute, Lelystad, The Netherlands) as adjuvant.

\section{Lipid Staining}

Ferritin fractions were stained with Oil Red $\mathrm{O}(\mathrm{BDH})$ and Sudan Black B (Merck) to check for differences in lipid composition between both ferritin fractions.

\section{Statistical Analysis}

Data sets were analyzed with a Bonferroni $t$-test following a "repeated-measures analysis of variance" to test differences in amino acid and carbohydrate composition between the three ferritin fractions.

\section{RESULTS}

Porcine spleen ferritin isolated according to the two procedures described and henceforward referred to as "crude" ferritin, always yielded two distinct bands when applied to a native 4-15\% gradient gel (Fig. 1, lane 4) on the Phastsystem. A vague third band (Fig. 1, lane 3) with an estimated mass of around $880 \mathrm{kDa}$, appeared more clearly when the ferritin solution was left to stand for a number of weeks. The marker proteins (Fig. 1, lane $1 \& 7$ ) defined the largest band $(=\mathrm{FFL})$ to be located around $440 \mathrm{kDa}$ and a second major band (=FFH) around $670 \mathrm{kDa}$. The two dark spots at the top of lane 4 (Fig. 1) might be ferritin oligomers and/ or aggregates with a molecular weight over $1000 \mathrm{kDa}$, which were unable to penetrate the separating gel. Similar results were obtained with native gradient gels $(8-25 \%)$ on a mini protean system (BioRad). Both major bands were also distinctly present in commercially available horse spleen and human placental ferritin (courtesy Dr J. P. van Dijk). In each sample, both bands stained positively for protein and iron. Densitometric analyses showed that about $30 \%$ of fresh porcine spleen ferritin was located in the FFH band (Fig. 1, lane: 4).

Applying "crude" ferritin samples to the two serially linked Sepharose columns (see Materials and Methods) resulted in a nearly complete separation of the FFL and FFH bands (see Fig. 1, lanes 5 and 6). Densitometric analysis of native gradient gels showed each band to be over $96 \%$ pure 


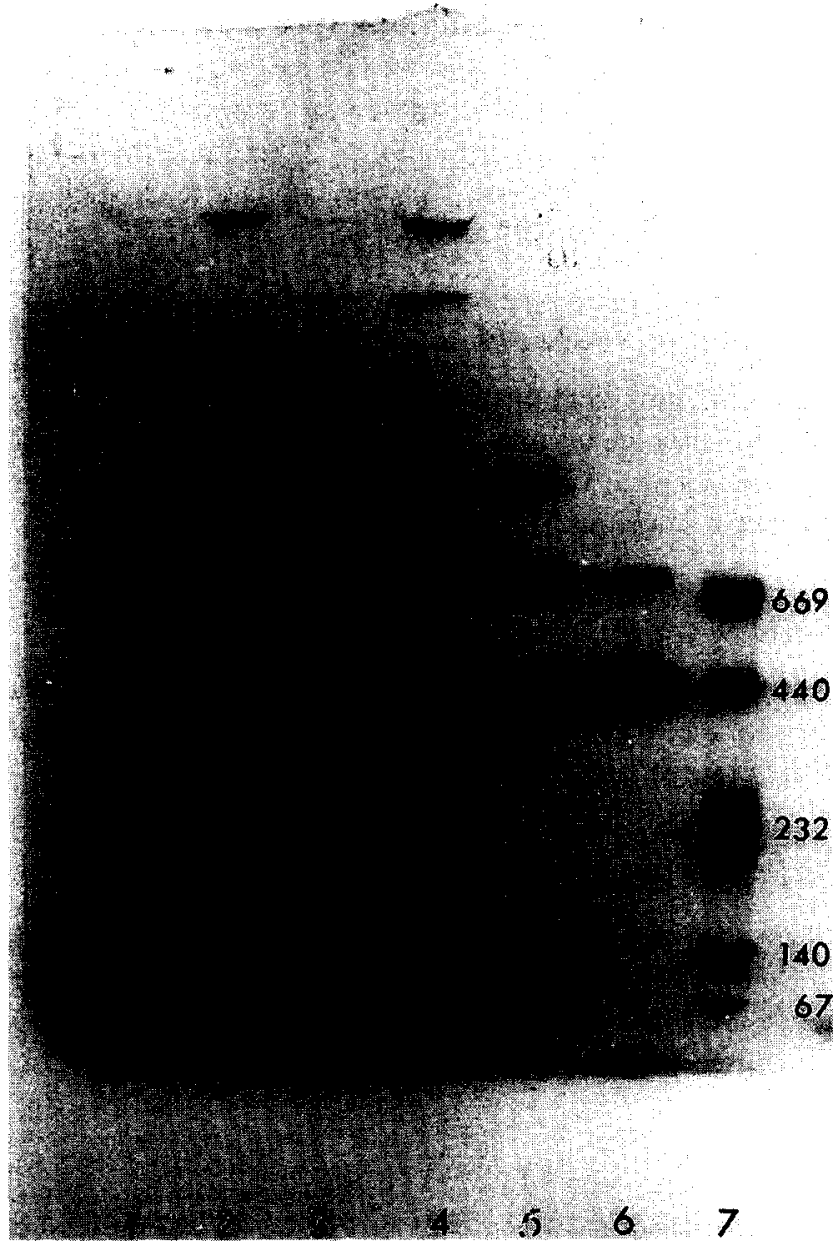

FIG. 1. Native polyacrylamide gel, 4-15\% gradient. Samples obtained after separation on two linked Sepharose $4 B$ and 6B columns. Lane 1: high molecular weight marker (in kDa). Lane 2: first iron-rich peak to appear during gelfiltration. Lane 3: peak appearing during gel-filtration prior to the FFH peak, consisting of ferritin aggregates and/or oligomers. Lane 4: "crude" ferritin fraction (no gel-filtration). Lane 5: FFH (670 kDa ferritin fraction) after second chromatographic run. Lane 6: FFL (440 kDa ferritin fraction) after second chromatografic run, purity $89 \%$. Lane 7 : high molecular weight marker (in $\mathrm{kDa}$ ).

after three chromatographic runs. The chromatographic separation pattern is shown in Fig. 2. Low magnification electron micrographs of both FFL and FFH revealed a similar heterogeneity in distribution pattern. An apparently random pattern of loose ferritin particles as well as small cluster of (up to 10) ferritin particles is found in samples of both fractions (Fig 3).

The L-and H-subunit composition of "crude" ferritin and both the purified FFL and FFH fractions were assessed using both SDS-PAGE and Tricine SDS-PAGE. Results of the $16.5 \%$ Tricine SDS-PAGE are shown in Fig. 4. Densitometric analysis confirmed a predominance of $L$-subunits in each of the samples and the $L$ to $H$ ratios in the three samples were not significantly different (i.e. $\pm 60 \%$ L subunits).
Table 1 summarizes iron to phosphorus ratios. Biochemically obtained data are compared to results determined by EPMA. As no difference was found between data acquired from ferritins applied to the support film or lying "stretched over the holes" in the film, the EPMA ratios given are the mean of combined data sets.

The means of six individual amino acid analyses of three batches of "crude" porcine spleen ferritin and both fractions are summarized in Table 2 . Only the $N$-acetyl glucosamine content of the FFL and FFH fractions was significantly different $(p<0.02)$ as shown by repeated-measures analysis of variance, followed by a Bonferroni $t$-test.

Carbohydrate and sialic acid analyses of all fractions are shown in Table 3. Despite some variation in glucose content between batches; a consistent $5: 1$ ratio in total carbohydrate content (a 10:1 ratio for sialic acid) was found between FFL and FFH respectively.

Staining with Sudan Black B or Oil Red O yielded negative results in both FFL and FFH fractions. Antibodies generated against the FFL and FFH ferritins and tested in an Ouchterlony against both fractions show differences in precipitation pattern (see Fig. 5).

\section{DISCUSSION}

To obtain a porcine spleen ferritin of high purity we used two modified standard procedures, which yielded in each case two distinct bands (FFL and FFH), appearing at 440 and $670 \mathrm{kDa}$ respectively in non-denaturating gradient gel electrophoresis (Figs. 1 and 2). Native gradient electrophoresis was repeated on another system with gels from another manufacturer, yielding identical results. Using the same procedure, we obtained similar bands in horse spleen and human placental ferritin.

Previously, a band appearing above $440 \mathrm{kD}$ had been considered as a ferritin dimer (39). The FFH fraction might in fact be a dimer of $440 \mathrm{kDa}$ ferritin, showing a different electrophoretic mobility due to loss of its spherical structure (15). We tried to facilitate dimer formation by leaving purified FFL and FFH to stand for a number of weeks at $4^{\circ} \mathrm{C}$ and then subjecting it again to non-denaturating gradient gel electrophoresis $(4-15 \%)$. After this procedure, a new band appeared in the stacking part of the gel above the $\mathrm{FFH}$ hand. According to manufacturer's information, the $4-15 \%$ gradient gel will exclude molecules above $1000 \mathrm{kDa}$ and this band could therefore consist of ferritin oligomers and/ or aggregates. In the FFL lane on the other hand, no extra bands appeared. So the FFL showed no tendency at all to form oligomers or aggregates (25).

Gel filtration chromatography was applied to separate both fractions (see Fig. 2). Based on the results in nondenaturating gel electrophoresis, there appeared to be a $50 \%$ difference in molecular weight between both fractions. However, considerable column dimensions $(4 \mathrm{~m})$ and repeated chromatographic runs (up to five times) were neces- 

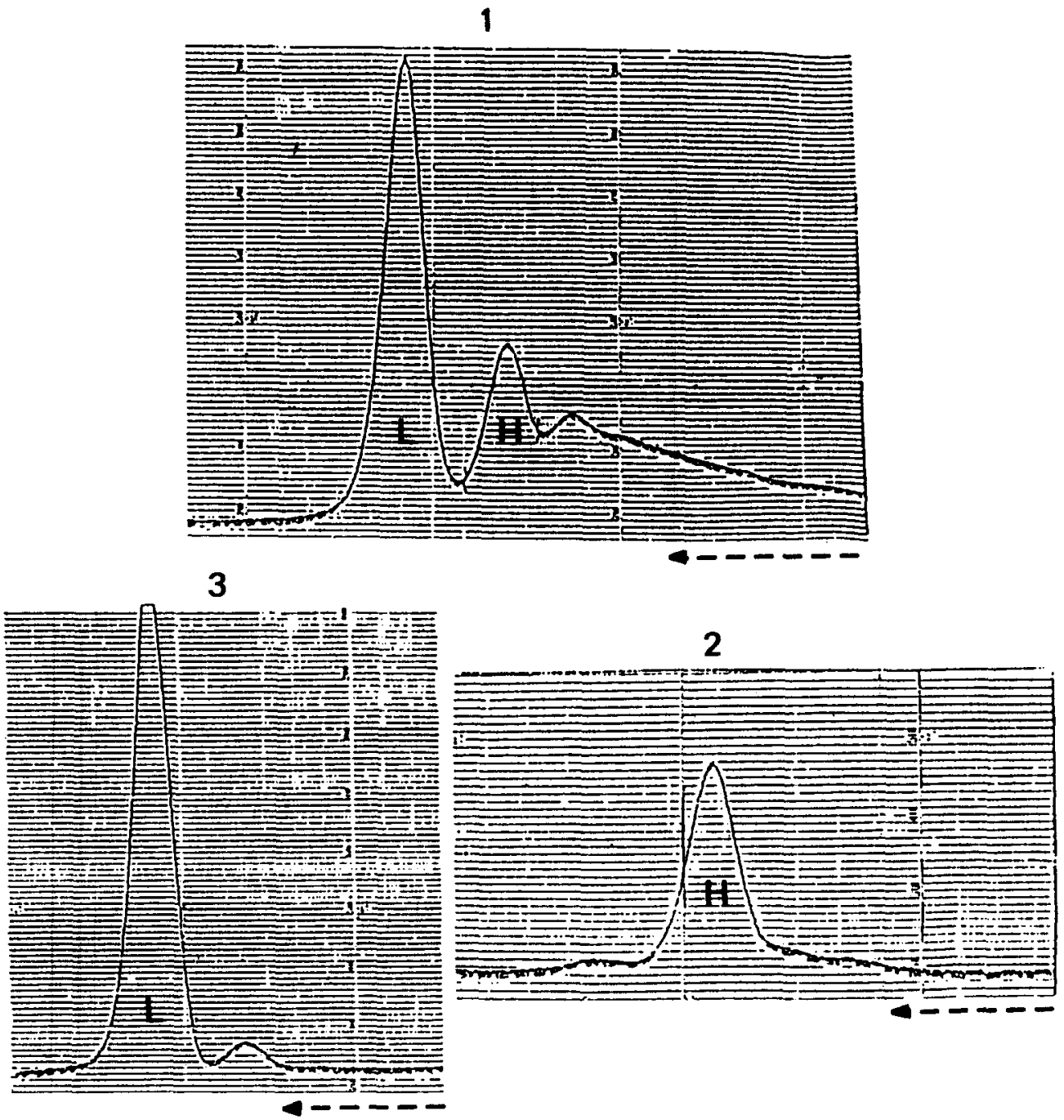

FIG. 2. Graphic displays of chromatographic runs to separate FFL (L) and FFH (H). 1: Freshly isolated ferritin applied as described in Materials and Methods; first chromatographic run. 2: Partially purified FFH, third chromatographic run. 3: Partially purified FFL, third chromatographic run. Arrows indicate direction of registration.

sary to accomplish separation with an acceptable degree of purity. It would therefore appear that the difference in mass berween the FFL and FFH fractions was less than suggested by nondenaturating gradient gel electrophoresis. Unfortunately, $K_{a x}$ values of Sepharose $4 \mathrm{~B}$ and $6 \mathrm{~B}$ gels are nearly equal for two fractions of this apparent size (15). An estimation of the difference in molecular mass between the two fractions, based on the difference in behaviour of FFL and FFH in the chromatographic run, is therefore not possible.

Electron micrographs of FFL and FFH revealed no morphological differences (see Fig. 3). Both fractions, sampled and prepared as described by Williams and Harrison (39), do display a random distribution of ferritin particles as such, and in aggregates of two, three or more particles. This suggests that in both cases aggregates are formed after application of the FFL and FFH samples to the grid. We supposed that our FFH is not a di- or oligomeric ferritin (40) fraction as seen by Williams and coworkers $(15,20)$. EM observations confirm those as reported by Richter $(25,30)$. These authors stated that ferritin particle aggregation could be attributed to the sample preparation technique (e.g. airdrying, dilution factor and so on).

Molecular weight estimates of proteins based on the results in non-denaturating gel electrophoresis are unreliable, for electrophoretic mobility of a protein in this type of analysis is not only affected by its mass, but also by its size, shape and number of side chains. Since SDS gel electrophoresis would cause the ferritin molecule to fall apart (15), we performed another series of experiments to further elucidate the nature of the difference in electrophoretic behaviour of the two ferritin fractions.

I) We could exclude that the apparent difference in mass between both fractions was due to a difference in iron load. First, both bands stained for iron, which excluded the possi- 


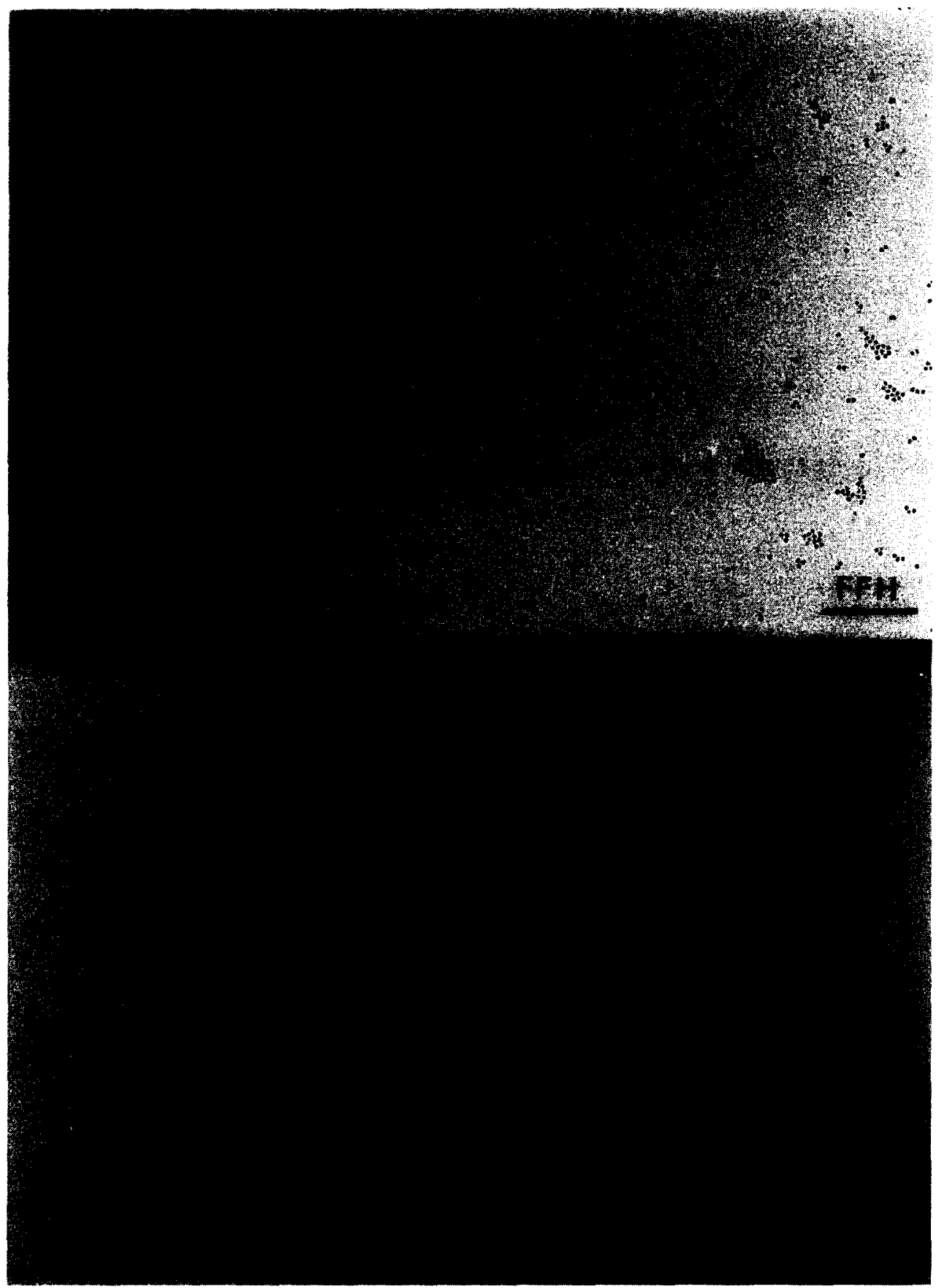

FIG. 3. Low power electronmicrograph of FFL $(440 \mathrm{kDa}$ fraction) and FFH $(670 \mathrm{kDa}$ fraction). Note the similarity in distribution pattern of the ferritin particles. Bar represents $200 \mathrm{~nm}$.

bility that one fraction was in fact apoferritin. Second, the absence of a smear between both bands (Fig. 1, lane 4) suggested against a variation in iron content. Biochemical assays, quantitating the amount of iron per molecule ferritin in "crude" ferritin and the purified fractions (Table 1) confirmed that the iron load of the FFL and FFH was not significantly different. Moreover, high power electron micrographs did not show any difference in iron core diameter between both fractions.

The iron to phosphorus ratio was assessed biochemically and with electron probe micro analysis (Table 1) because biochemical determination of phosphorus is not very reliable at low concentrations. The ratio showed no significant difference between FFL and FFH. However, compared to "crude" ferritin, there is either a loss of phosphorus or an increase in iron in both fractions (17). According to our data (Table 1), the amount of iron per molecule of ferritin is equal in all fractions. Therefore, we have to assume a loss of phosphorus in both fractions for which we have no explanation.

II) A difference in subunit composition between both fractions was ruled out, as samples of "crude" ferritin and 


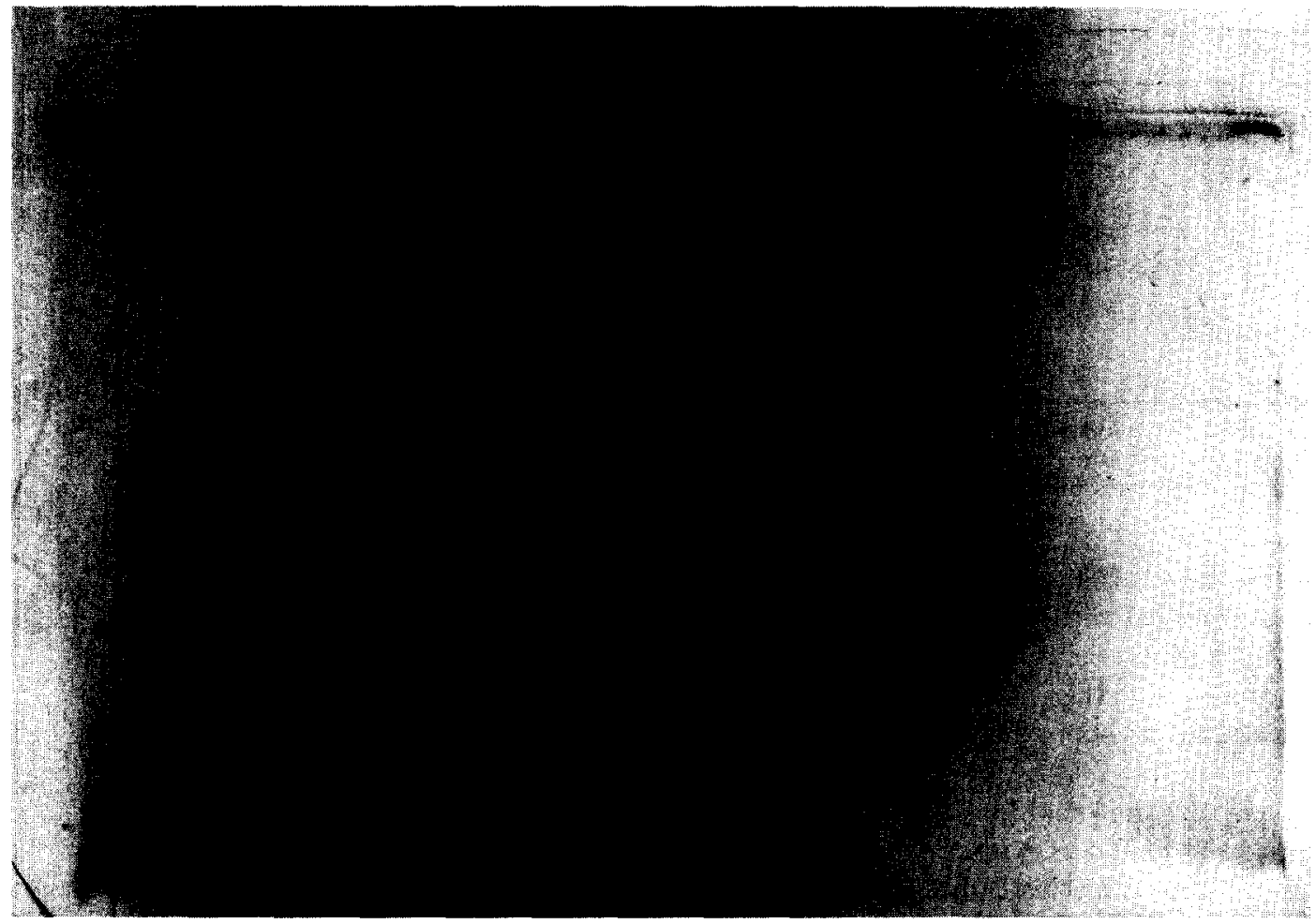

FIG. 4. Tricine-SDS polyacrylamide gel $(16.5 \% \mathrm{~T} ; 3 \% \mathrm{C})$. Samples were obtained after separation on a Sephadex G $200 \mathrm{column}$. Lane 1: $440 \mathrm{kDa}$ fraction (FFL) after fourth chromatografic run. Lane 2: $670 \mathrm{kDa}$ fraction (FFH) after third chromatographic run. Lane 3: "crude" ferritin. Lane 4: low molecular weight marker (in kDa).

TABLE 1. Fe/protein and $\mathrm{Fe} / \mathrm{P}$ ratios in different ferritin fractions

\begin{tabular}{lccc}
\hline $\begin{array}{l}\text { Porcine spleen } \\
\text { ferritins }\end{array}$ & $\begin{array}{c}\text { mol Fe/mol } \\
\text { ferritin } \\
(\mathbf{n}=6)\end{array}$ & $\begin{array}{c}\text { Fe/P ratio } \\
\text { (biochem.) } \\
(\mathbf{n}=6)\end{array}$ & $\begin{array}{c}\text { Fe/P ratio } \\
\text { (EPMA) } \\
(\mathbf{n}=\mathbf{3 0})\end{array}$ \\
\hline "crude" ferritin & $1700 \pm 219$ & $8.3 \pm 1.1 \#$ & $17.5 \pm 4.9 \#$ \\
FFH (670 kDa) & $1675 \pm 244$ & $23.5 \pm 11.5$ & $31.9 \pm 13.3$ \\
FFL (440 kDa) & $1638 \pm 132$ & $30.3 \pm 21.2$ & $33.6 \pm 14.4$
\end{tabular}

Data were obtained from three individual isolation procedures in duplicate. $A$ \# indicates a significant difference $(P<0.05)$ from the other values in that column.

purified FFL and FFH showed only minor differences in $\mathrm{L}$ and $\mathrm{H}$ subunit composition when applied to a SDS- or a Tricine SDS-PAGE (Fig. 4).

III) Santambrogio and Massover $(32,33)$ discovered on non-denaturating gels an additional band in rabbit liver ferritin, consisting of ferritin associated to alpha-2-macroglobulin. Although this finding would seem to fit the description of our FFH, our experimental results indicated otherwise, as in both fractions (i) SDS-PAGE and Tricine SDS-PAGE showed only 19 and $21 \mathrm{kDa}$ bands, (ii) Amino acid analyses (see below) revealed no significant differences, and (iii) Ouchterlony double immunodiffusion against rabbit anti-porcine-serum protein antibodies showed no precipitation.
TABLE 2. Relative amino acid composition of different ferritin fractions

\begin{tabular}{lccc}
\hline $\begin{array}{l}\text { Rel. \% } \\
\text { amino acids }\end{array}$ & $\begin{array}{c}\text { "Crude" } \\
\text { ferritin }\end{array}$ & $\begin{array}{c}\text { FFH } \\
\text { fraction }\end{array}$ & $\begin{array}{c}\text { FFL } \\
\text { fraction }\end{array}$ \\
\hline Asp & 11.6 & 12.6 & 12.8 \\
Thr & 4.8 & 4.2 & 3.9 \\
Ser & 9.3 & 7.0 & 6.6 \\
Glu & 14.1 & 15.0 & 16.0 \\
Gly & 8.4 & 8.3 & 7.5 \\
Ala & 8.3 & 8.3 & 7.5 \\
Val & 4.5 & 4.1 & 3.8 \\
Met & 2.2 & 2.0 & 2.2 \\
Ile & 2.4 & 2.1 & 1.6 \\
Leu & 1.0 & 11.6 & 12.8 \\
Trp & $\#$ & $\#$ & $\#$ \\
Tyr & 3.2 & 3.2 & 3.3 \\
Phe & 3.9 & 3.9 & 4.2 \\
GlcNH ${ }_{2}^{*}$ & 0.6 & 1.0 & 0.4 \\
His & 3.7 & 3.9 & 4.3 \\
Lys & 5.4 & 5.7 & 5.7 \\
Arg & 5.2 & 5.4 & 5.9 \\
5 Cys & $\#$ & $\#$ & $\#$ \\
Total & $98.6 \%$ & $98.3 \%$ & $98.5 \%$ \\
\hline
\end{tabular}

Data were obtained in duplicate from three individual isolation procedures. Results were expressed as means of six data sets. * Indicates a significant difference between the FFL (440 kDa) and FFH (670 kDa).

\# Indicates omission of analysis. 
TABLE 3. Carbohydrate analyses of different ferritin fractions

\begin{tabular}{lccc}
\hline $\begin{array}{l}\text { Carbohydrate residues } \\
\text { (mol/mol) }\end{array}$ & $\begin{array}{c}\text { “Crude" } \\
\text { ferritin }\end{array}$ & $\begin{array}{c}\text { FFH } \\
\text { fraction }\end{array}$ & $\begin{array}{c}\text { FFL } \\
\text { fraction }\end{array}$ \\
\hline Mannose & 14 & 20 & 5 \\
Glucose & 39 & 100 & 25 \\
Galactose & 48 & 80 & 11 \\
Sialic acid & 10 & 1 \\
\% Carbohydrates/ferritin & 3 & $8.9 \%$ & $1.8 \%$ \\
$\quad$ (w/w) & $4.3 \%$ & & \\
\hline
\end{tabular}

Carbohydrate and sialic acid residues are expressed in $\mathrm{mol} / \mathrm{mol}$ protein. Data were obtained in duplicate from three individual isolation procedures. Results were significantly different within the three fractions $(P<0.01)$.

IV) Antibodies generated against each of the purified ferritin fractions crossreacted with samples of both FFL and FFH in an Ouchterlony. However, the pattern of arcs deviating from the larger "ring" (Fig. 5) differs. It would therefore appear that the two fractions are not completely identical.

V) Finally, averaged amino acid analyses of FFL and FFH showed no significant differences, with the exception of $N$. acetylglucosamine (Table 2). This carbohydrate residue is an essential element in the core structure of $N$-linked glycans (16). We therefore assumed a difference in ferritin glycosylation and subjected each fraction to carbohydrate analysis. These analyses showed a circa 5 to 1 carbohydrate ratio $(w / w)$ between FFH and FFL. The difference in sialic acid composition was even more pronounced (Table 3). In all analyses, the results of "crude" ferritin fitted inbetween ( $\mathrm{Ta}$ ble 3).

This difference in carbohydrate content will not explain the apparent differences in mass $( \pm 230 \mathrm{kDa}$ ) between both fractions, as shown in non-denaturating gel electrophoresis. However, carbohydrate chains will affect the size and shape of ferritin, as they occupy a larger volume than globular proteins of the same molecular size. Differences in carbohydrate side chains will therefore he reflected in a difference in the electrophoretic and chromatographic behaviour of FFL and FFH.

\section{SUMMARY}

Porcine spleen ferritin isolated as described above shows two distinct bands in non-denaturating gradient gel electrophoresis. The two fractions (FFL and FFH) acquired in this way are equal as judged by electron microscopy in morphological appearance and, as assessed biochemically, in subunit composition, iron load and amino acid composition (except for $N$-acetylglucosamine). On the other hand, FFL and FFH differ in carbohydrate content and show incomplete homology when crossreacted with antibodies generated against both fractions.

Little is known about the physiological/biological significance of sialylation of proteins. Speculation with respect

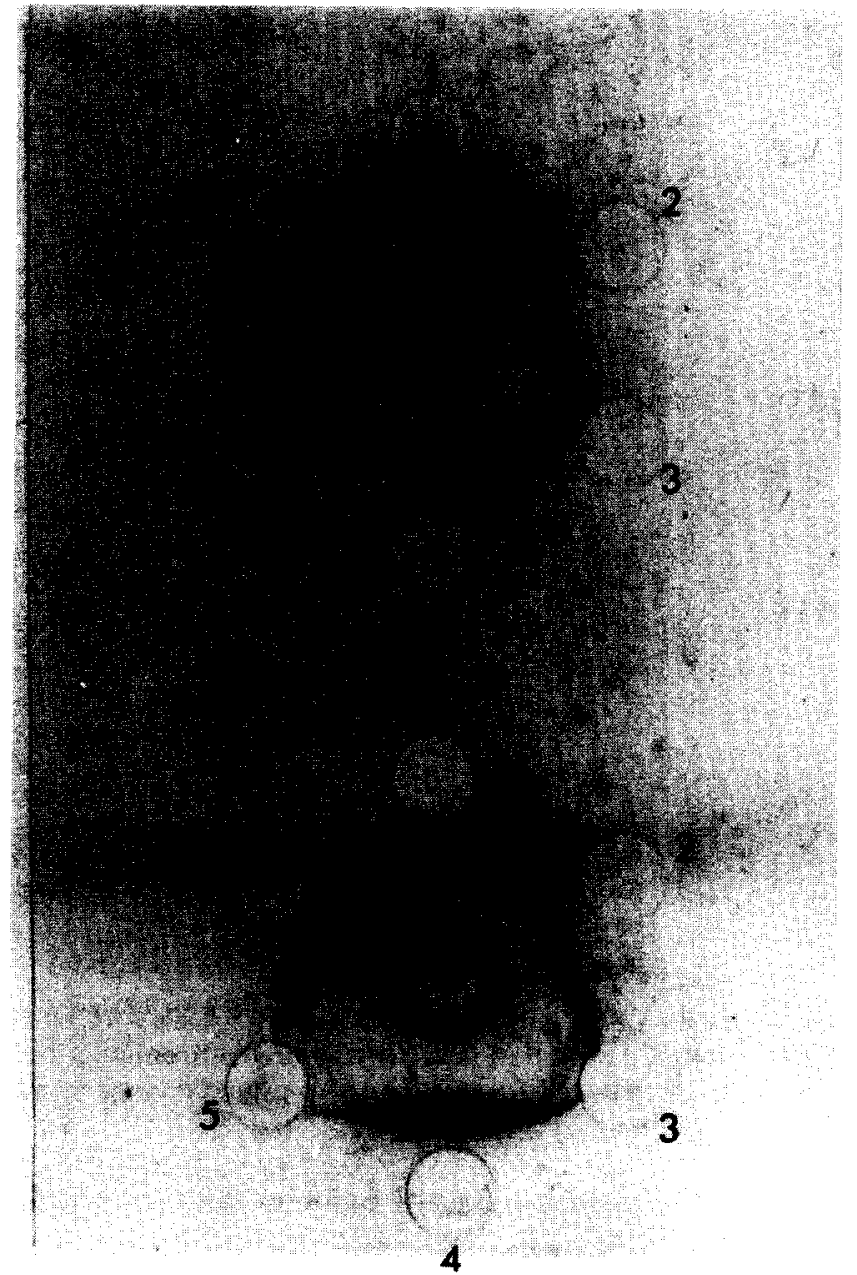

FIG. 5. Polyclonal antibodies generated against the purified 440 and $670 \mathrm{kDa}$ ferritin fractions (anti-FFL and -FFH) were tested against FFL and FFH in an Ouchterlony double immunodiffusion assay. $A$ : anti-FFL; $B$ : anti-FFH. 1: FFL (undiluted); 2: FFH (undiluted). 3: FFL (diluted 1:2). 4: FFH (diluted 1:2). 5: FFL (diluted 1:5); 6: FFH (diluted 1:5).

to the biological function of the difference in carbohydrates in our two fractions are therefore not fruitful at this stage.

The authors would like to thank Prof. P. M. Harrison for the fruitful discussion and Drs A. Mirza and C. Hukshorn for their assistance in the isolation of tissue ferritins. They would also like to express their gratitude to Mr wan der Zom and coworkers of the "Rotterdamse Varkensslachterij"' for their generous supply of porcine tissue.

\section{References}

1. Aisen, P. Iron transport and storage proteins. Ann. Rev. Biochem. 49:357-393;1980.

2. Ames, B.N. Assay of inorganic phosphate, total phosphate and phosphatases. Methods of Enzymology 8:115-118;1966.

3. Aminoff, $D$. Methods for the quantitative estimation of $N$. acetylneuraminic acid and their application to hydrolysates of sialomucoids. Biochem. J. 81:384-392;1961.

4. Andrews, S.C. A new form of ferritin heterogeneity explained. Isolation and identification of a nineteen-amino-acid 
residue fragment from siderosomal ferritin of rat liver. Biochem. J. 245:447-453;1987.

5. Berenblum, I.; Chain, E. An improved method for the colorimetric determination of phosphate. Biochem. J. 32:295-298; 1938.

6. Bradford, M.M. A rapid and sensitive method for the quantification of microgram quantities of proteins utilizing the principles of protein-dye binding. Analytical Biochemistry 72: 248-251;1976.

7. Chung, M.C-M. A specific iron stain for iron-binding proteins in polyacrylamide gels: Application to transferrin and lactoferrin. Analytical Biochemistry 148:498-502;1985.

8. Cleton, M.I.; Frenkel, E.J.; de Bruin, W.C.; Marx, J.M. Determination of iron to phosphorus ratios of iron storage compounds in patients with iron overload: a chemical and electron probe X-ray microanalysis. Hepatology 5:848-851; 1986.

9. Collawn, J.F.; Lau, P.Y.; Morgan, S.L.; Fox, A.; Fish, W.W. A chemical and physical comparison of ferritin subunit species fractionated by high-performance liquid chromatography. Arch. Biochem. Biophys. 233(1):260-266;1984.

10. Collawn, J.F.; Gowan, L.K.; Crow, H.; Schwabe, C.; Fish, W.W. Isolation and partial amino acid sequence of three subunit species of porcine spleen ferritin; evidence of multiple $\mathrm{H}$ subunits. Arch. Biochem. Biophys. 259(1):105-113;1987.

11. Cragg, S.J.; Wagstaff, M.; Worwood, M. Detection of a glycosylated subunit in human serum ferritin. Biochem. J. 199:565$571 ; 1980$.

12. Cragg, S.J.; Wagstaff, M.; Worwood, M. Sialic acid and the microheterogeneity of human serum ferritin. Clinical Science 58:259-262;1981.

13. Crichton, R.R. Primary structure of horse and human apoferritins. In: Urushizaki, I.; Aisen, P.; Listowski, J.; Drysdale, J.W. (eds). Structure and function of iron storage and transport proteins. Amsterdam: Elsevier Science; 1983:3-10.

14. Cynkin, M.A.; Knowlton, J. Studies on the carbohydrate components of ferritin. In: Brown, E.B.; Aisen, Ph.; Fielding, J.; Crichton, R.R. (eds). Proteins of iron metabolism. New York: Grune and Stratton; 1977:115-120.

15. DeHaën, C. Molecular weight standards for calibration of gel filtration and sodium dodecyl sulfate-polyacrylamide gel electrophoresis: ferritin and apoferritin. Analytical Biochemistry $166: 235-245 ; 1987$.

16. De Jong, G.; van Dijk, J.P.; van Eijk, H.G. The biology of transferrin. Clinica Chimica Acta 190:1-46;1990.

17. De Silva, D.; Guo, J.H.; Aust, S.D. Relationship between iron and phosphate in mammalian ferritins. Arch. Biochem. Biophys. 303(2):451-455;1993.

18. Drysdale, J.W. Ferritin phenotypes: structure and metabolism. Ciba Foundation Symposium 71. Iron Metabolism. 1977:4157.

19. Harris, D.C. Iron exchange between ferritin and transferrin in vitro. Biochemistry 17:3071-3078;1978.

20. Harrison, P.M.; Gregory, D.W. Evidence for the existence of stable "aggregates" in horse spleen ferritin and apoferritin. Journal of Molecular Biology 14:626-629;1965.

21. Harrison, P.M.; Hoare, R.J.; Hoy, T.G.; Macara, I.G. Ferritin and haemosiderin: structure and function. In: Jacobs, A.; Worwood, M. (eds). Iron in biochemistry and medicine. London: Academic Press; 1974:73-114.

22. Horgan, I.E. A modified spectrophotometric method for determination of nanogram quantities of sialic acid. Clinica Chimica Acta 116:409-415;1981.

23. Konijn, A.M.; Tal, R.; Levy, R.; Matzner, Y. Isolation and fractionation of ferritin from human placenta-A source for human isoferritins. Analytical Biochemistry 144:423-428; 1985.

24. Lavoie, D.J.; Marcus, D.M.; Ishikawa, K.; Listowski, I. Ferritin and apoferritin from human liver: aspects of heterogeneity. In: Brown, E.B.; Aisen, P.; Fielding, J.; Crichton, J.J. (eds). Proteins of iron metabolism. New York: Grune and Stratton; 1977:71-78.

25. Lee, S.S.C.; Richter, G.W. The monomers and oligomers of ferritin and apoferritin: association and dissociation. Bio. chemistry 15:65-70;1976.

26. Linder, M.; Goode, C.A.; Gonzalez, R.; Gottschling, C.; Gray, J.; Nagel, G.M. Heart tissue contains small and large aggregates of ferritin subunits. Arch. Biochem. Biophys. 273(1): 34-41;1989.

27. Munro, H.N.; Linder, M.C. Physiological Reviews. Ferritin: Structure, Biosynthesis and Role in Iron metabolism. American Journal of Physiology 58(2):317-396;1978.

28. Passaniti, A.; Roth, T.F. Purification of chicken liver ferritin by two novel methods and structural comparison with horse spleen ferritin. Biochem. J. 258:413-419;1989.

29. Penders, T.J.; De Rooij-Dijk, H.H.; Leijnse, B. Rapid isolation of ferritin by means of ultracentrifugation. Biochemica et Biophysica Acta, 168;588-590;1968.

30. Richter, G.W.; Walker, G.F. Reversible association of apoferritin molecules. Comparison of light-scattering and other data. Biochemistry 6:2871-2880;1967.

31. Sala, G.; Worwood, M.; Jacobs, A. The effect of isoferritins on granulopoiesis. Blood, 67(2):436-443;1986.

32. Santambrogio, P.; Massover, W.H. Protein heterogeneity in rabbit liver ferritin: two types of molecular dimers. Biochemical and Biophysical Research Communications 148(3):1363$1369 ; 1987$

33. Santambrogio, P.; Massover, W.H. Rabbit serum alpha-2 macroglobulin binds to liver ferritin: association causes a heterogeneity of ferritin molecules. British Journal of Haematology 71:281-290;1989.

34. Schägger, $H_{\text {; }}$ von Jagow, G. Tricine-sodium dodecyl sulfate polyacrylamide gel electrophoresis for the separation of proteins in the range from 1 to $100 \mathrm{kDa}$. Analytical Biochemistry 166:368-379;1987.

35. Shinjyo, S.; Abe, H.; Masuda, M. Carbohydrate composition of horse spleen ferritin. Biocheimica et Biophysica Acta 411: $165-167 ; 1975$.

36. Van Eijk, H.G.; van Noort, W.L. The reliability of the use of paratoluene sulfonic acid for simultaneous hydrolysis and quantitation of both $\mathrm{N}$-acetyl-glucosamine and amino acids in human transferrins. Clinica Chimica Acta 157:305-310; 1986.

37. Van Noort, W.L.; van Eijk, H.G. Quantification of monosaccharides occurring in glycoproteins at subnanomole levels using an automated LC analyzer. LC-GC International 3(5):50$52 ; 1990$.

38. Van Noort, W.L.; De Jong, G.; van Eijk, H.G. Purification of isotransferrins by concanavalin A sepharose chromatography and preparative isoelectric focusing. European Journal of Clinical Chemistry and Clinical Biochemistry 32(12):885-892; 1994.

39. Williams, M.A.; Harrison, P.M. Electronmicroscopic and chemical studies of oligomers in horse ferritin. Biochem. J. 110:265-280;1968.

40. Yang, D.; Matsubara, K.; Yamaki, M.; Ebina, S.; Nagayama, $K$. Heterogeneities in ferritin dimers as characterized by gel filtration, nuclear magnetic resonance, electrophoresis, transmission electron microscopy, and gene engineering techniques. Biochimica et Biophysica Acta 1206:173-179;1994. 